\title{
Oncological outcomes following radical prostatectomy for patients with pT4 prostate cancer
}

Dharam Kaushik ${ }^{1,2}$, Stephen A. Boorjian ${ }^{1}$, R. Houston Thompson ${ }^{1}$, Manuel S. Eisenberg ${ }^{1}$, Rachel E. Carlson ${ }^{3}$, Eric J. Bergstralh ${ }^{3}$, Igor Frank ${ }^{1}$, Matthew T. Gettman ${ }^{1}$, Matthew K. Tollefson ${ }^{1}$, R. Jeffrey Karnes ${ }^{1}$

${ }^{1}$ Department of Urology, Mayo Clinic, Rochester, Minnesota, USA; ${ }^{2}$ Department of Urology, University of Texas Health Science Center, San Antonio, Texas, USA; ${ }^{3}$ Division of Biomedical Statistics and Informatics, Mayo Clinic, Rochester, Minnesota, USA

\section{ABSTRACT}

Objectives: Radical prostatectomy (RP) for locally advanced prostate cancer may reduce the risk of metastasis and cancer-specific death. Herein, we evaluated the outcomes for patients with pT4 disease treated with RP.

Materials and methods: Among 19,800 men treated with RP at Mayo Clinic from 1987 to 2010, 87 were found to have pT4 tumors. Biochemical recurrence (BCR)-free survival, systemic progression (SP) free survival and overall survival (OS) were estimated using the Kaplan-Meier method and compared with the log-rank test. Cox proportional hazards regression models were used to assess the association of clinic-pathological features with outcome.

Results: Median follow-up was 9.8 years (IQR 3.6, 13.4). Of the 87 patients, 50 (57.5\%) were diagnosed with BCR, 30 (34.5\%) developed SP, and 38 (43.7\%) died, with 11 $(12.6 \%)$ dying of prostate cancer. Adjuvant androgen deprivation therapy was administered to 77 men, while 32 received adjuvant external beam radiation therapy. Tenyear BCR-free survival, SP-free survival, and OS was 37\%, 64\%, and 70\% respectively. On multivariate analysis, the presence of positive lymph nodes was marginally significantly associated with patients' risk of BCR (HR: 1.94; $\mathrm{p}=0.05)$, while both positive lymph nodes (HR 2.96; p=0.02) and high pathologic Gleason score (HR 1.95; p=0.03) were associated with SP.

Conclusions: Patients with pT4 disease may experience long-term survival following $\mathrm{RP}$, and as such, when technically feasible, surgical resection should be considered in the multimodal treatment approach to these men.

\section{ARTICLE INFO}

\section{Keywords:}

Prostatic Neoplasms;

Prostatectomy; Neoplasm

Metastasis

Int Braz J Urol. 2016; 42: 1091-8

Submitted for publication:

May 19, 2016

Accepted after revision:

May 23, 2016

Published as Ahead of Print:

September 20, 2016

\section{INTRODUCTION}

In 2016 there will be approximately 180,890 new cases of prostate cancer and 26.120 related deaths in the US (1). Despite the noted stage migration in prostate cancer over the course of the PSA era, approximately 10\% of patients present with locally advanced disease, which increa- ses the risk of disease progression and mortality after initial treatment (2). Historically, the majority of patients with high-risk prostate cancer have been managed with external beam radiation therapy (EBRT) and androgen deprivation therapy (ADT) (3-6).

More recently, several observational series have demonstrated the technical feasibility of 
radical prostatectomy (RP) in the setting of highrisk disease and have reported 5-year progressionfree survival rates of approximately 85\% (7-10). While in high-risk disease, surgery is often a component of a multimodal treatment approach; $\mathrm{RP}$ provides accurate pathologic staging of both the primary tumor and pelvic lymph nodes and may afford durable local control. Of note, the majority of surgical series on locally advanced disease have consisted of patients with either clinical or pathologic T3 tumors. Indeed, the treatment outcomes and prognostic variables for patients with pT4 prostate cancer remain poorly described. Here, we evaluated our experience with RP for patients in whom the final pathologic analysis demonstrated pT4 disease. Specifically, we analyzed the long-term rates of biochemical recurrence (BCR), systemic progression (SP) and overall survival (OS) following surgery as part of a multimodal treatment approach. Furthermore, we identified clinico-pathologic variables associated with oncological outcome in these men.

\section{MATERIALS AND METHODS}

\section{Patient selection}

After Institutional Review Board approval (\#12-007416) was obtained, we reviewed our Prostatectomy Registry and identified 19,800 patients who underwent RP between 1987 and 2010. Surgical procedures were performed using standard techniques. For the uniformity of diagnosis and staging, all the cases were reviewed by central pathology laboratory and surgical specimens were processed according to standard pathological procedures and staged according to the 2009 American Joint Committee on Cancer staging system for prostate cancer (11). A total of 87 men were found to have pT4 disease, and form the study cohort here. Out of these, 7 patients underwent robotic radical prostatectomy with pelvic lymph node dissection (PLND) and 80 underwent radical retropubic prostatectomy with PLND. Pelvic lymph node dissection was performed utilizing the following template-we completely removed all lymph node tissue along the external iliac vein, the distal limit being the deep circumflex vein and the femoral canal. We removed all fibrofatty tissue from the obturator fossa to completely skeletonize the obturator nerve. Proximally, PLND was performed up to and including the bifurcation of the common iliac artery. The lateral limit consisted of the pelvic sidewall, and the medial dissection limit was defined by perivesical fat. In high-risk patients included in our cohort, LNs along the internal iliac vessels were dissected.

The retrospective nature of our dataset precludes a standardized approach to surveillance; however, postoperative assessments, including physical examination and serum PSA measurement, were generally done quarterly for the initial 2 years after surgery, semi-annually for an additional 2 years, and annually thereafter. Adjuvant therapy was defined as treatment received $\leq 90$ days of RP, and was given at the discretion of the treating physician, while salvage therapy was defined as treatment received $>90$ days after RP, and was likewise administered based on clinician's discretion. BCR was defined as a PSA level of $\geq 0.4 \mathrm{ng} / \mathrm{mL}$ (12). SP was defined as demonstrable metastasis on radionuclide bone scan or on biopsies outside the prostatic bed. Vital status was identified from death certificates or physician correspondence. For patients followed elsewhere, the Mayo Clinic Prostatectomy Registry prospectively monitors outcomes annually by correspondence.

\section{Statistical analysis}

Continuous features were summarized with medians and interquartile ranges (IQR); categorical features were summarized with frequency counts and percentages. The Kaplan-Meier method was utilized to estimate BCR-free survival, SP-free survival and OS, with differences assessed with log-rank test. Patients were censored at last follow-up or death if the endpoint of interest had not been attained. Cox proportional hazards model was used to estimate the association of clinic-pathologic variables with patient's risk of BCR, SP, and all-cause mortality. Statistical analysis was done using $\mathrm{SAS}^{\circledR}$, version 9.2. All tests were two-sided, with $\mathrm{p} \leq 0.05$ considered to indicate statistical significance. 


\section{RESULTS}

Of 19,800 patients who underwent RP during the time period of study, we identified 87 $(0.43 \%)$ patients with pT4 disease. Median age at surgery in these men was 65 years (IQR 58, 69). Median preoperative PSA was $12.2 \mathrm{ng} / \mathrm{mL}$ (IQR5.7, 34.9). Table- 1 lists the clinic-pathological features for this cohort. Moreover, 30 (34.5\%) and 4 (4.6\%) patients received androgen deprivation therapy (ADT) and external beam radiation therapy (EBRT), respectively, prior to RP.

Median follow-up after RP was 9.8 years (IQR 3.6, 13.4), during which time 50 patients ex-

Table 1 - Clinical and pathological features of pT4 prostate cancer patients.

\begin{tabular}{cc}
\hline & Total $(\mathrm{n}=87)$ \\
\hline Clinical T Stage & $(\mathrm{n}=85)$ \\
T1c & $15(17.6 \%)$ \\
T2a & $20(23.5 \%)$ \\
T2b & $11(12.9 \%)$ \\
T3/4 & $39(45.9 \%)$ \\
Biopsy Gleason Score & $(\mathrm{n}=54)$ \\
$\leq 6$ & $13(24.1 \%)$ \\
7 & $14(25.9 \%)$ \\
$8-10$ & $27(50.0 \%)$ \\
Pathological Gleason Score & $(\mathrm{n}=79)$ \\
$\leq 6$ & $12(15.2 \%)$ \\
7 & $32(40.5 \%)$ \\
$8-10$ & $35(44.3 \%)$ \\
Seminal vesicle invasion & $(\mathrm{n}=86)$ \\
No & $24(27.9 \%)$ \\
Yes & $62(72.1 \%)$ \\
Nodal status & $(\mathrm{n}=87)$ \\
Negative & $47(54.0 \%)$ \\
Positive & $40(46.0 \%)$ \\
Positive surgical margin & $(\mathrm{n}=87)$ \\
No & $5(5.7 \%)$ \\
Age at Surgery & \\
N & $(\mathrm{n}=87)$ \\
Median & $65.0(\mathrm{IQR}: 58-69)$ \\
Pre-op PSA (ng/mL) & \\
N & $(\mathrm{n}=76)$ \\
Median & $12.2(\mathrm{IQR}: 5.7-34.9)$ \\
Race & $(\mathrm{n}=87)$ \\
Caucasian & $67(77.0 \%)$ \\
Other & $1(1.1 \%)$ \\
Undetermined & $19(21.8 \%)$ \\
\hline & \\
\hline & \\
\hline &
\end{tabular}

perienced BCR, 10 were diagnosed with a local recurrence, 30 developed SP and 38 died, with 11 dying of prostate cancer. A total of 77 men were treated with adjuvant $\mathrm{ADT}$, while 32 received adjuvant EBRT. We noted that the 10-year BCR-free survival in these patients was $37 \%$, while $64 \%$ were free from SP and the overall survival was 70\% (Figure-1).

We then further stratified patient's risk of SP by pathological Gleason score, and lymph node status. As such, the Kaplan-Meier analysis with the log rank test showed that for patients with pT4 tumors, both higher Gleason score and positive lymph node status showed differences in progression between the groups. The 10-year SP-free survival for patients with a pT4 Gleason 8-10 tumor was $47 \%$, versus $72 \%$ for patients with a Gleason 7 tumor and 82\% for patients with Gleason 6 disease $(p=0.028)$ (Figure-2). Likewise, the 10-year SP-free survival for patients with positive lymph nodes was $45 \%$, versus $81 \%$ for pT4NO tumors ( $\mathrm{p}=0.002)$ (Figure-3).

Moreover, on multivariate analysis (Table-2), positive lymph node status was found to be marginally significantly associated with patient's risk of BCR [HR 1.94, $\mathrm{p}=0.05$ ], while both positive lymph nodes [HR 2.96, $\mathrm{p}=0.02$ ] and higher pathological Gleason score [HR 1.95, $\mathrm{p}=0.03$ ] were associated with a significantly increased risk for systemic progression in these men. Ten-year survival estimates for BCR, SP and OS grouped by pathological Gleason Score, median prior PSA and receipt of prior treatment are shown in Table-3.

\section{DISCUSSION}

We report the natural oncological outcomes of patients with pT4 disease treated with RP. In this cohort, we found that over one-third of patients remained free of BCR at 10 years after surgery, while the 10-year overall survival for these men was 70\%. In addition, we noted that both high pathologic Gleason score and lymph node involvement contributed to the development of metastatic disease in these men.

While the outcomes for patients with locally-advanced prostate tumors treated with surgery 
Figure 1 - Kaplan-Meier plot showing 10-year Overall Survival, Systemic progression and biochemical recurrence.

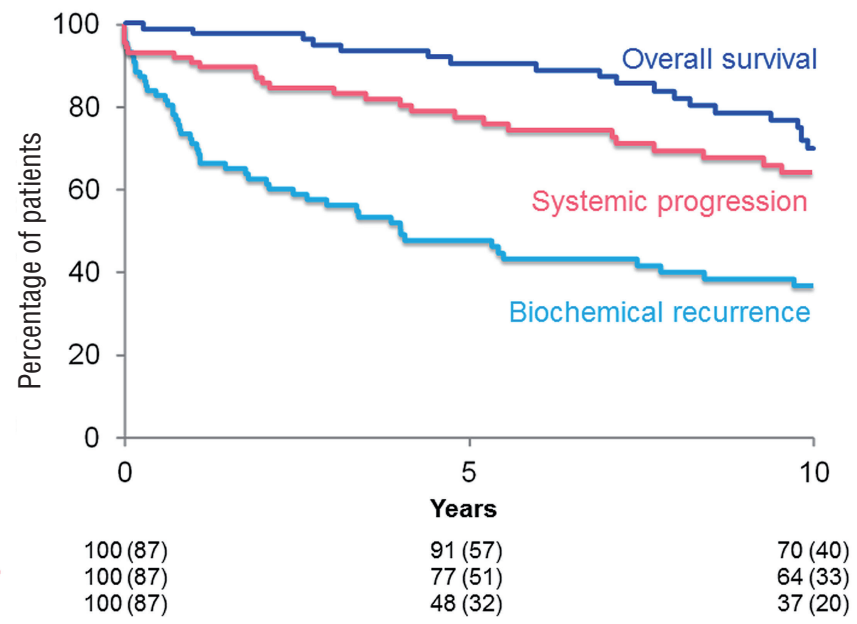

Figure 2 - Kaplan-Meier plot showing Systemic-progression stratified by Gleason-score.

Systemic Progression Stratified By Gleason Score

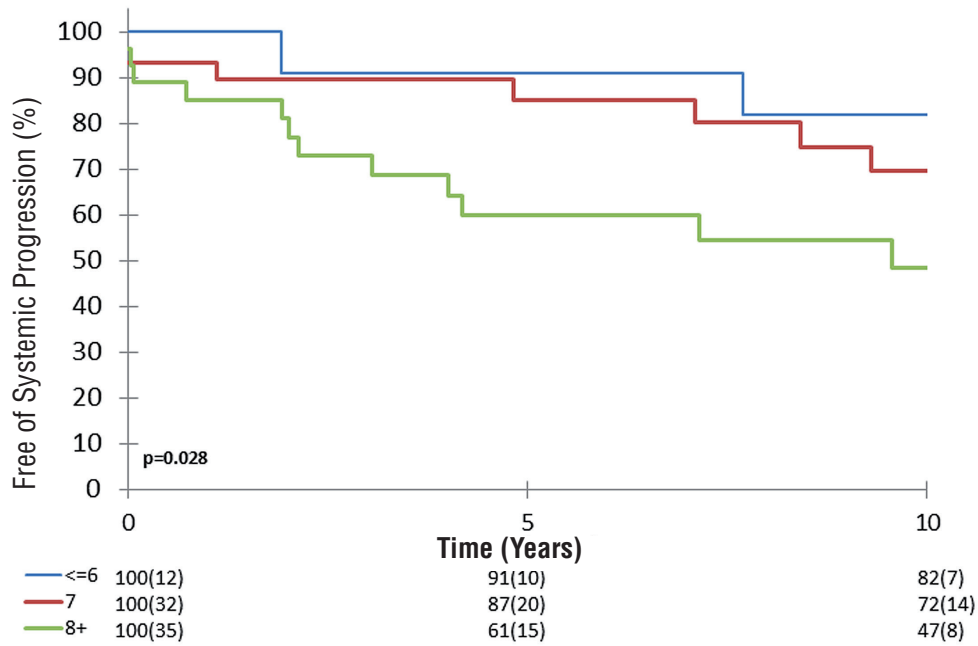

have been previously described, $(7,10,13)$ these series have primarily focused on T3 tumors and, as such, the present study represents what is, to our knowledge, the first report to specifically focus on pT4 prostate cancer treated with RP. Likewise, while prior series have reported long-term survival following surgery in patients with lymph-node positive disease (14), our data further provide evidence of a role for surgery in the setting of very high-risk prostate cancer. Indeed, even in patients with pT4N1 disease, the highest-risk patients, nearly half of such men were without evidence of clinical metastases at 10 years after RP. 
Figure 3 - Kaplan-Meier plot showing Systemic-progression stratified by nodal status.

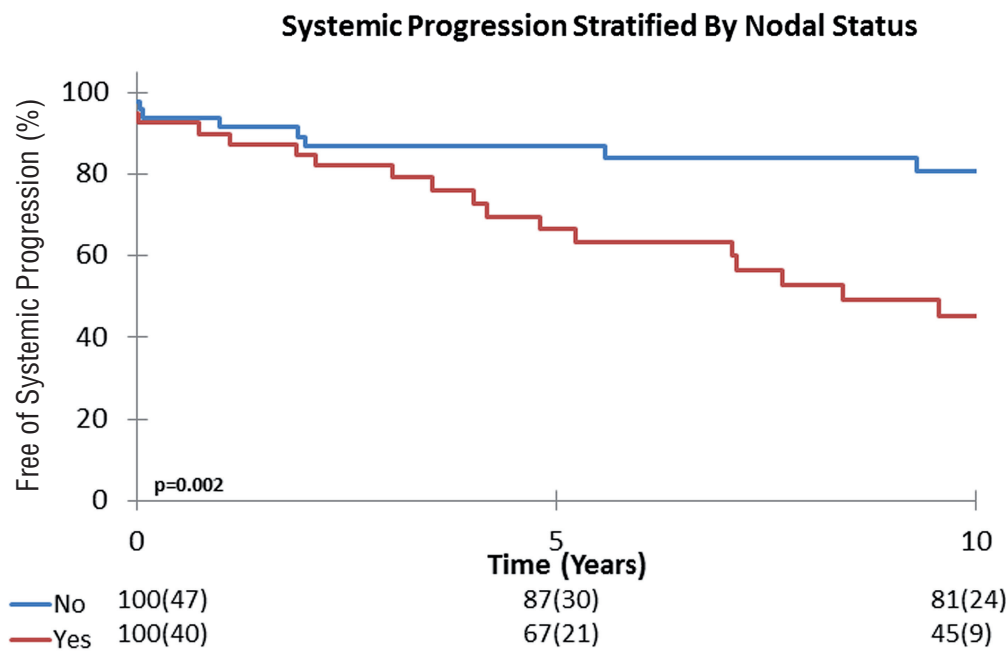

Table 2 - Multivariate analysis of factors associated with biochemical recurrence, systemic progression and all-cause mortality.

\begin{tabular}{|c|c|c|c|c|c|c|c|c|c|}
\hline & \multicolumn{3}{|c|}{$\begin{array}{l}\text { Biochemical Failure } \\
\text { (46 events) }\end{array}$} & \multicolumn{3}{|c|}{$\begin{array}{l}\text { Systemic Progression } \\
\text { (27 events) }\end{array}$} & \multicolumn{3}{|c|}{$\begin{array}{c}\text { Death } \\
\text { (29 events) }\end{array}$} \\
\hline & HR & $95 \% \mathrm{Cl}$ & $\mathrm{p}$-value & HR & $95 \% \mathrm{Cl}$ & p-value & HR & $95 \% \mathrm{Cl}$ & p-value \\
\hline Path Gleason Score Group & 1.17 & $(0.78-1.75)$ & 0.42 & 1.95 & $(1.04-3.60)$ & 0.03 & 1.06 & $(0.61-1.81)$ & 0.83 \\
\hline Log 2 preoperative PSA (doubling) & 1.13 & $(0.95-1.36)$ & 0.15 & 0.94 & $(0.74-1.19)$ & 0.65 & 1.14 & $(0.88-1.47)$ & 0.30 \\
\hline Treatment prior to RP & 1.62 & $(0.89-2.94)$ & 0.11 & 1.85 & $(0.83-4.13)$ & 0.12 & 1.003 & $(0.44-2.28)$ & 0.99 \\
\hline Positive lymph nodes & 1.94 & $(1.01-3.72)$ & 0.05 & 2.96 & $(1.20-7.29)$ & 0.02 & 1.37 & $(0.60-3.11)$ & 0.44 \\
\hline Seminal vesicle invasion & 1.36 & $(0.64-2.87)$ & 0.42 & 3.91 & $(0.86-17.63)$ & 0.07 & 1.76 & $(0.62-5.03)$ & 0.28 \\
\hline
\end{tabular}

Table 3 - Survival estimates for biochemical recurrence, systemic progression and overall survival.

\begin{tabular}{cccc}
\hline & $\begin{array}{c}\text { 10-year Survival Estimates for } \\
\text { Biochemical recurrence (\%) }\end{array}$ & $\begin{array}{c}\text { 10-year Survival Estimates for } \\
\text { Systemic Progression (\%) }\end{array}$ & $\begin{array}{c}\text { 10-year Survival Estimates for } \\
\text { Overall Survival (\%) }\end{array}$ \\
\hline $\begin{array}{c}\text { Path Gleason Score } \\
<=6\end{array}$ & 47 & 82 & 73 \\
7 & 42 & 72 & 78 \\
$8+$ & 24 & 47 & 68 \\
PSA (ng/DL) & & & 76 \\
$<=12.2$ & 41 & 64 & 68 \\
$>12.2$ & 35 & 66 & \\
Prior Treatment & & & 70 \\
No & 49 & 73 & 69 \\
Yes & 11 & 45 & 70 \\
\hline
\end{tabular}


Level-1 data exist regarding the role of EBRT and androgen deprivation therapy (ADT) in management of locally advanced prostate cancer. In Bolla et al. trial, out of 415 patients, $89 \%$ were high risk (cT3/T4) with reported 5 year-OS in combined EBRT/ADT group to be 79\% compared to $62 \%$ in the radiotherapy group alone (5). In the SPCG-7/SFU0-3 trial, 880 patients, predominantly cT3NOMO, were randomly assigned to either ADT or ADT with EBRT. Ten-year OS was better in the EBRT/ADT arm compared to ADT only arm (70\% vs. 60\%) (3). Both these trials provided evidence supporting addition of local radiotherapy to endocrine treatment had an important effect on overall and cancer-specific mortality in locally advanced prostate cancer. Importantly, these studies confirm the critical role of local tumor control in addition to systemic therapies.

Because of the heterogeneous population of locally-advanced prostate cancer and lack of data from randomized trials comparing RP and EBRT, definitive inferences cannot be reached regarding the relative effectiveness of each treatment modality for achieving long-term cancer control. There have been few retrospective comparative studies; while 2 studies have shown superior biochemical relapse-free survival with EBRT in comparison to RP, $(15,16)$ one study has shown better metastasis-free survival (17) and another studying showing better overall survival with RP compared to EBRT/ADT (18).

Interestingly, Thompson et al. evaluated 1,286 men with metastatic disease from the Southwest Oncology Group Study 8894 and determined that patients who underwent RP prior to developing metastatic disease had lower risk of death than patients who did not (HR 0.77 [0.53, 0.89]) (19). Multiple hypotheses may be offered to support a benefit for RP in advanced stage prostate cancer, including prevention of development of metastatic disease from primary tumor (19).

Zelefsky et al. (17) reviewed a cohort of 2,380 patients who either underwent RP or EBRT and evaluated them for systemic progression-free survival and cancer-specific survival (CSS). On their multivariate analysis, RP was found to be associated with reduced risk of developing me- tastatic disease in comparison to EBRT, especially in high-risk patients (HR 0.35; $\mathrm{p}<0.001$ ).

In addition, as the management for patients with locally advanced prostate cancer is likely to involve a multi-modal approach, RP as the initial treatment affords accurate pathologic staging, which may thereby guide the selective application of secondary therapy. That is, up to $25 \%$ of patients with clinical T3 tumors in fact have organ-confined disease at surgery (20). As such, RP may facilitate the identification of patients with pathologic extraprostatic disease who might benefit from adjuvant RT (21) as well as patients with positive lymph nodes, who might benefit from adjuvant ADT (22). Further, as the extension of locally advanced tumors may result in debilitating loco-regional symptoms including recurrent hematuria, pelvic pain, as well as urinary, rectal and ureteral obstruction, the durable local control with surgery noted here (only 11.5\% of the patients have experienced a local recurrence) may improve patient's quality of life as well. Indeed, a higher rate of hospital admissions, rectal or anal procedures, and open surgical procedures has been noted in patients treated with radiotherapy for prostate cancer versus patients treated with surgery (23).

Primary RP with PLND remains the only method that provides conclusive pathological evidence and excellent loco-regional control as shown by low local recurrence rate of $11.5 \%$ in our study. With data from the Southwest Oncology Group (SWOG 8794) for the use of adjuvant radiation therapy in high-risk patients (21), and Messing trial results demonstrating an advantage in survival for long-term ADT in lymph node-positive patients (22), good pathologic data are an important step toward multi-modality approach. Admittedly, the optimal management for patients with locally advanced prostate cancer remains to be determined, ideally in a prospective clinical trial setting. Nevertheless, there remains an absence of comparative level I evidence. We recognize that our study is limited by its retrospective design. Further, although the entity of pT4 disease at $\mathrm{RP}$ is uncommon, we acknowledge the relatively small patient sample size here. Likewise, it must be acknowledged that this cohort represents a highly 
selective cohort of patients, and, as noted above, the optimal treatment for such men remains to be determined. Nevertheless, we believe that surgery represents a component of the often multi-modal approach for locally advanced prostate cancer, and may be associated with favorable long-term survival.

In conclusion, radical prostatectomy with pelvic lymph node dissection in the setting of locally advanced prostate cancer is associated with durable loco-regional control and definitive pathologic staging, which in turn facilitates the selective application of secondary therapies. As such, surgical resection should continue to be considered in the multi-modal treatment approach to these men.

\section{CONFLICT OF INTEREST}

\section{None declared.}

\section{REFERENCES}

1. Siegel RL, Miller KD, Jemal A. Cancer statistics, 2016. CA Cancer J Clin. 2016;66:7-30.

2. Mohler JL, Armstrong AJ, Bahnson RR, Boston B, Busby JE, D’Amico AV, et al. Prostate cancer, Version 3.2012: featured updates to the NCCN guidelines. J Natl Compr Canc Netw. 2012;10:1081-7.

3. Widmark A, Klepp 0, Solberg A, Damber JE, Angelsen A, Fransson $P$, et al. Endocrine treatment, with or without radiotherapy, in locally advanced prostate cancer (SPCG7/SFU0-3): an open randomised phase III trial. Lancet. 2009:373:301-8. Erratum in: Lancet. 2009:373:1174.

4. Bolla M, Collette L, Blank L, Warde P, Dubois JB, Mirimanoff $\mathrm{RO}$, et al. Long-term results with immediate androgen suppression and external irradiation in patients with locally advanced prostate cancer (an EORTC study): a phase III randomised trial. Lancet. 2002;360:103-6.

5. Bolla M, Gonzalez D, Warde P, Dubois JB, Mirimanoff RO, Storme G, et al. Improved survival in patients with locally advanced prostate cancer treated with radiotherapy and goserelin. N Engl J Med. 1997;337:295-300.

6. Meng MV, Elkin EP, Latini DM, Duchane J, Carroll PR. Treatment of patients with high risk localized prostate cancer: results from cancer of the prostate strategic urological research endeavor (CaPSURE). J Urol. 2005;173:1557-61.
7. Ward JF, Slezak JM, Blute ML, Bergstralh EJ, Zincke H. Radical prostatectomy for clinically advanced (cT3) prostate cancer since the advent of prostate-specific antigen testing: 15-year outcome. BJU Int. 2005;95:751-6.

8. Powell IJ, Tangen CM, Miller GJ, Lowe BA, Haas G, Carroll $P R$, et al. Neoadjuvant therapy before radical prostatectomy for clinical T3/T4 carcinoma of the prostate: 5-year followup, Phase II Southwest Oncology Group Study 9109. J Urol. 2002;168:2016-9.

9. Loeb S, Smith ND, Roehl KA, Catalona WJ. Intermediateterm potency, continence, and survival outcomes of radical prostatectomy for clinically high-risk or locally advanced prostate cancer. Urology. 2007;69:1170-5.

10. Carver BS, Bianco FJ Jr, Scardino PT, Eastham JA. Longterm outcome following radical prostatectomy in men with clinical stage T3 prostate cancer. J Urol. 2006;176:564-8.

11. Edge SB, American Joint Committee on Cancer. Prostate. AJCC Cancer Staging Manual. 7th ed. Springer, New York 2010;457-68.

12. Amling CL, Bergstralh EJ, Blute ML, Slezak JM, Zincke H. Defining prostate specific antigen progression after radical prostatectomy: what is the most appropriate cut point? J Urol. 2001;165:1146-51.

13. Freedland SJ, Partin AW, Humphreys EB, Mangold LA, Walsh PC. Radical prostatectomy for clinical stage T3a disease. Cancer. 2007;109:1273-8.

14. Bader P, Burkhard FC, Markwalder R, Studer UE. Disease progression and survival of patients with positive lymph nodes after radical prostatectomy. Is there a chance of cure? J Urol. 2003;169:849-54.

15. Kuefer R, Volkmer BG, Loeffler $M$, Shen RL, Kempf $L$, Merseburger AS, et al. Comparison of external radiation therapy vs radical prostatectomy in lymph node positive prostate cancer patients. Prostate Cancer Prostatic Dis. 2004;7:343-9.

16. Fletcher SG, Mills SE, Smolkin ME, Theodorescu D. Casematched comparison of contemporary radiation therapy to surgery in patients with locally advanced prostate cancer. Int J Radiat Oncol Biol Phys. 2006;66:1092-9.

17. Zelefsky MJ, Eastham JA, Cronin AM, Fuks Z, Zhang Z, Yamada $Y$, et al. Metastasis after radical prostatectomy or external beam radiotherapy for patients with clinically localized prostate cancer: a comparison of clinical cohorts adjusted for case mix. J Clin Oncol. 2010;28:1508-13.

18. Boorjian SA, Karnes RJ, Viterbo R, Rangel LJ, Bergstralh EJ, Horwitz EM, et al. Long-term survival after radical prostatectomy versus external-beam radiotherapy for patients with high-risk prostate cancer. Cancer. 2011;117:2883-91.

19. Thompson IM, Tangen C, Basler J, Crawford ED. Impact of previous local treatment for prostate cancer on subsequent metastatic disease. J Urol. 2002;168:1008-12. 
20. Mitchell CR, Boorjian SA, Umbreit EC, Rangel LJ, Carlson RE, Karnes RJ. 20-Year survival after radical prostatectomy as initial treatment for CT3 prostate cancer. BJU Int. 2012;110:1709-13.

21. Thompson IM, Tangen CM, Paradelo J, Lucia MS, Miller G, Troyer D, et al. Adjuvant radiotherapy for pathological T3NOMO prostate cancer significantly reduces risk of metastases and improves survival: long-term followup of a randomized clinical trial. J Urol. 2009;181:956-62.

22. Messing EM, Manola J, Sarosdy M, Wilding G, Crawford $E D$, Trump D. Immediate hormonal therapy compared with observation after radical prostatectomy and pelvic lymphadenectomy in men with node-positive prostate cancer. N Engl J Med. 1999;341:1781-8.
23. Nam RK, Cheung P, Herschorn S, Saskin R, Su J, Klotz LH, et al. Incidence of complications other than urinary incontinence or erectile dysfunction after radical prostatectomy or radiotherapy for prostate cancer: a population-based cohort study. Lancet Oncol. 2014;15:223-31.

Correspondence address:

Dharam Kaushik, MD

Department of Urology

University of Texas Health Science Center

San Antonio, Texas

7703 Floyd Curl Drive

San Antonio, TX 78229-3900, USA

Fax: +1 210 567-6868

E-mail:kaushik@uthscsa.edu 